\title{
Attitudes Towards Mental Health Services During the COVID-19 Pandemic: Findings from a Nationally Representative Sample of Irish Adults
}

\author{
Christa McCutchen MA \\ Philip Hyland PhD \\ Pádraig Ó Féich PhD
}

\begin{abstract}
This study sought to determine the public's attitudes towards mental health services during the COVID-19 pandemic and examine the sociodemographic and psychological factors associated with these attitudes to gain an understanding of the best course of action to increase favourable attitudes. Data from the Republic of Ireland arm of the COVID-19 Psychological Research Consortium (C19PRC) study was used to fulfil the objectives of this study. Participants were asked to indicate their level of agreement with statements regarding mental health services and the COVID19 pandemic. Levels of agreement were then scored, and the relationships between attitude scores and sociodemographic and psychological factors were evaluated utilizing hierarchical multiple regression analysis. Sociodemographic factors associated with positive attitudes towards mental health were older age, experience with mental health treatment, and experience with internalizing distress. These factors should be considered when developing strategies to increase favourable public attitudes towards mental health services in Ireland.
\end{abstract}

Address correspondence to Christa McCutchen, Department of Psychology, Maynooth University, Kildare, Ireland. christa.mccutchen.2022@mumail.ie.

Address correspondence to Philip Hyland, Department of Psychology, Maynooth University, Kildare, Ireland. christa. mccutchen.2022@mumail.ie.

Pádraig Ó Féich, Mental Health Reform, Dublin, Ireland.

The Journal of Behavioral Health Services \& Research, 2022. 397-405 . (c) 2022, National Council for Mental Wellbeing, . DOI 10.1007/s11414-021-09785-x 
Despite fears that the COVID-19 pandemic would adversely affect the mental health of the general population ${ }^{1}$, the empirical evidence indicates that there was only a small and briefly lasting increase in symptoms of anxiety and depression at the outset of the pandemic ${ }^{2}$, and most people experienced no change, or an improvement, in their mental health within the first year of the pandemic ${ }^{3}$. Nevertheless, the pandemic brought greater public attention to the issue of public mental health needs, and it has been suggested that stigma associated with mental health problems may consequently decline ${ }^{4}$. It is important, therefore, to evaluate the public's attitudes to various mental health issues in the context of the COVID-19 pandemic and to understand what the public believe about the need for resources for mental health services and the responsibility of government to respond to mental health needs. Moreover, identifying key sociodemographic and psychological factors associated with attitudes towards mental health issues provides an opportunity to understand who in the population holds favourable or unfavourable attitudes towards mental health issues and why they hold such attitudes. Developing these understandings creates an opportunity to implement strategies to increase favourable attitudes towards mental health issues.

\section{Method}

\section{Participants and procedures}

This study used data from the Republic of Ireland arm of the COVID-19 Psychological Research Consortium (C19PRC) ${ }^{5}$. Participants were recruited from traditional, actively managed, research internet panels by the survey company Qualtrics using email, SMS, or in-app notifications. Based on inclusion criteria, respondents were 18 years of age or older, resident of the Republic of Ireland, and capable of completing the survey in English. To ensure the sample was nationally representative, as per the 2016 Irish census ${ }^{6}$, quota sampling methods were used in terms of sex, age, and geographical distribution. Sample characteristics are presented in Table 1. Ethical approval was granted by the University of Sheffield.

\section{Measures \\ Mental health attitudes during COVID-19}

For this study, a six-item measure was developed by the research team to assess the public's attitudes about mental health issues during the COVID-19 pandemic. The six statements are shown in Figure 1. Participants were asked to indicate the extent to which they agreed with each statement on a five-point Likert scale ranging from 'strongly disagree' (1) to 'strongly agree' (5). To determine the optimal scoring scheme for this measure, a confirmatory factor analysis was undertaken. A one-factor model with weighted least squares mean- and variance-adjusted estimation ${ }^{7}$ provided acceptable fit to the sample data $\left(\chi^{2}(9,1032)=466.58, p<0.001 ; \mathrm{CFI}=0.95\right.$; $\mathrm{TLI}=0.92$; RMSEA $=0.22(90 \% \mathrm{CI}=0.21,0.24)$; SRMR $=0.04)$. Although the RMSEA indicated poor fit, this test has been shown to perform poorly in models with small degrees of freedom ${ }^{8}$. The six items loaded significantly $(p<0.001)$ onto the latent attitude variable, and all items had standardized factor loadings greater than 0.80 with the exception of item 3 which had a loading of 0.30 . Furthermore, the internal reliability of the six items was good $(\alpha=0.81)$. Thus, a summed score of the six items was used for analytic purposes, and scores of this attitudinal variable ranged from 6 to 30 with higher scores reflecting more favourable attitudes. 
Table 1

Sociodemographic characteristics of the sample $(N=1,032)$

\begin{tabular}{|c|c|c|}
\hline & $n$ & $\%$ \\
\hline Age & \multicolumn{2}{|c|}{$\mathrm{M}=44.86, \mathrm{SD}=15.74$} \\
\hline \multicolumn{3}{|l|}{ Sex } \\
\hline Male & 493 & 47.8 \\
\hline Female & 536 & 51.9 \\
\hline \multicolumn{3}{|c|}{ Born in the Republic of Ireland } \\
\hline Yes & 739 & 71.6 \\
\hline \multicolumn{3}{|l|}{ Living location } \\
\hline City & 209 & 20.3 \\
\hline Suburb & 221 & 21.4 \\
\hline Town & 294 & 28.5 \\
\hline Rural & 308 & 29.8 \\
\hline \multicolumn{3}{|c|}{ Highest educational attainment } \\
\hline No qualification & 15 & 1.5 \\
\hline Completed Junior/Inter cert & 63 & 6.1 \\
\hline Completed Leaving Cert & 221 & 21.4 \\
\hline Undergraduate degree & 229 & 22.2 \\
\hline Postgraduate degree & 204 & 19.8 \\
\hline Other qualifications & 21 & 2.0 \\
\hline Technical qualification & 122 & 11.8 \\
\hline \multicolumn{3}{|l|}{ Religion } \\
\hline Atheist & 150 & 14.5 \\
\hline Agnostic & 66 & 6.4 \\
\hline Christian & 748 & 72.5 \\
\hline Muslim & 17 & 1.6 \\
\hline Jewish & 1 & 0.1 \\
\hline Buddhist & 6 & 0.6 \\
\hline Sikh & 1 & 0.1 \\
\hline Other & 43 & 4.2 \\
\hline \multicolumn{3}{|l|}{2019 income } \\
\hline$€ 0-19,999$ & 256 & 24.6 \\
\hline$€ 20,000-29,999$ & 222 & 21.3 \\
\hline$€ 30,000-39,999$ & 203 & 19.5 \\
\hline$€ 40,000-49,999$ & 132 & 12.7 \\
\hline$€ 50,000$ or more & 228 & 21.8 \\
\hline \multicolumn{3}{|c|}{ First preference party vote in the 2020 general election } \\
\hline Fine Gael & 172 & 16.7 \\
\hline Fianna Fáil & 122 & 11.8 \\
\hline Sinn Féin & 204 & 19.8 \\
\hline Green Party & 63 & 6.1 \\
\hline Labour & 37 & 3.6 \\
\hline
\end{tabular}




\begin{tabular}{llr}
\hline & $n$ & $\%$ \\
\hline Social Democrats & 19 & 1.8 \\
Solidarity/People Before Profit & 18 & 1.7 \\
Aontú & 8 & 0.8 \\
Independent & 72 & 7.0 \\
Did not vote & 240 & 23.3 \\
Ineligible because too young & 9 & 0.9 \\
Ineligible because not an Irish citizen or resident & 68 & 6.6 \\
Mental health treatment history & & \\
Never received treatment for a mental health problem & 729 & 70.6 \\
Received treatment for a mental health problem in the past & 231 & 22.4 \\
Currently receiving treatment for a mental health problem & 72 & 7.0 \\
\hline
\end{tabular}

\section{Sociodemographic variables}

Eight sociodemographic variables were assessed including age, sex $(0=$ male, $1=$ female $)$, nationality $(0=$ Irish, $1=$ non-Irish), urbanicity $(0=$ non-city dwelling, $1=$ city dwelling), highest educational achievement $(0=$ post-secondary level, $1=$ secondary level or less $)$, religious identification $(0=$ atheist/agnostic, $1=$ any religion $)$, annual income $(0=$ less than $€ 20,000,1=€ 20,000-29,999$, $2=€ 30,000-39,999,3=€ 40,000-49,999,4=€ 50,000$ or more), current or past mental health treatment $(0=$ no, $1=$ yes $)$, and voted in the 2020 general election $(0=$ yes, $1=$ no).

\section{Psychological variables}

Internalizing distress A summed score of symptoms of posttraumatic stress disorder, major depression, and generalized anxiety was used to represent internalizing distress. The six-item International Trauma Questionnaire (ITQ) ${ }^{9}$, the Patient Health Questionnaire-9 (PHQ-9) ${ }^{10}$, and the Generalized Anxiety Disorder 7-item Scale (GAD-7) ${ }^{11}$ were used to measure the respective indicators of internalizing distress. Scores range from 0 to 72 with higher scores reflecting higher levels of distress. The internal reliability of the scale scores (i.e. the 22 items from the measures) was excellent $(\alpha=0.96)$.

Identification with others The nine-item Identification with all Humanity Scale (IWAHS) ${ }^{12}$ asks participants to indicate how much they identify with people in their community, from Ireland, and all humans everywhere. The response scale ranged from 'not at all' (1) to 'very much' (5), and higher scores reflect greater identification with others. The internal reliability of the IWAHS scores in this sample was excellent $(\alpha=0.93)$.

Personality traits The Big-Five Inventory (BFI) ${ }^{13}$ measures the five personality traits of openness, conscientiousness, extraversion, agreeableness, and neuroticism with two items on a five-point Likert scale ranging from 'strongly disagree' (1) to 'strongly agree' (5). Higher scores reflect higher levels of each trait. The BFI has been shown to produce scores with good reliability and validity. ${ }^{14}$ 


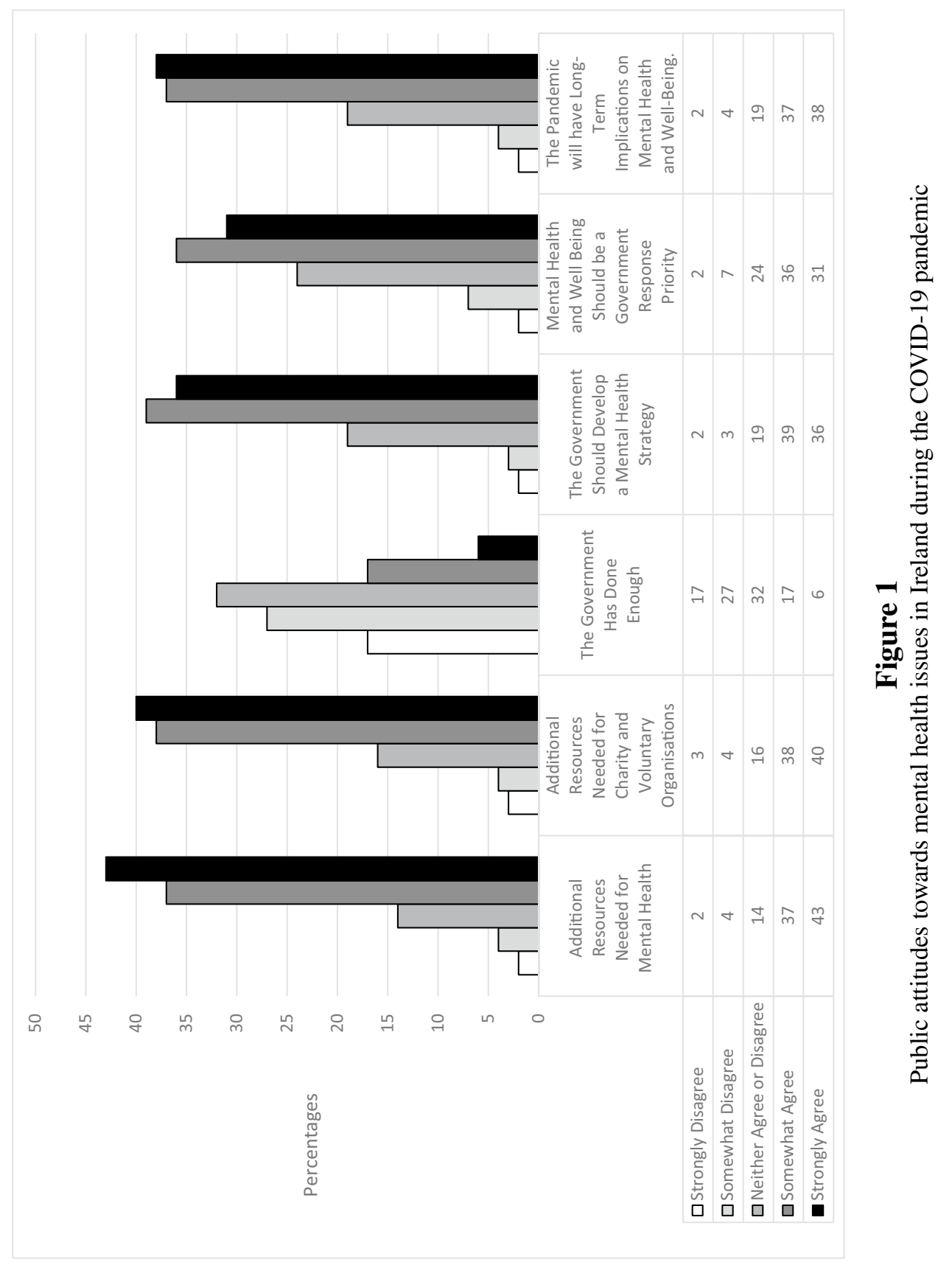


Since the BFI uses two items per trait, it was not possible to produce meaningful internal reliability estimates in this sample.

Internal locus of control The three-item 'Internal' subscale of the Locus of Control Scale ${ }^{13}$ was used. The questions were answered on a seven-point Likert scale ranging from 'strongly disagree' (1) to 'strongly agree' (7), and higher scores reflect higher levels of internal locus of control. The internal reliability of the scale score in this sample was good $(\alpha=0.77)$.

Death anxiety Death anxiety was measured using the 17-item Death Anxiety Inventory. ${ }^{15}$ Responses are based on a five-point Likert scale ranging from 'totally disagree' (1) to 'totally agree' (5). Death anxiety scores range from 17 to 85 with higher scores reflecting higher levels of death anxiety. The internal reliability of the scale scores in this sample was excellent $(\alpha=0.92)$.

Resilience Resilience was measured using the Brief Resilience Scale ${ }^{16}$ which includes six items answered on a five-point Likert scale ranging from 'strongly disagree' (1) to 'strongly agree' (5). Higher scores reflect higher levels of resilience, and the internal reliability of the scale scores in this samples was acceptable $(\alpha=0.69)$.

\section{Data analysis}

Descriptive statistics were calculated to determine what proportion of the sample agreed/disagreed with the six statements relating to mental health issues in Ireland. Hierarchical multiple regression analysis was used to identify the sociodemographic and psychological factors that were uniquely associated with mental health attitudes. The nine sociodemographic variables were added to the model in block 1, and the ten psychological variables were added in block 2 .

\section{Results}

The proportion of people who agreed/disagreed with the six attitudinal statements is presented in Figure 1. The majority 'somewhat' or 'strongly' agreed that additional resources were needed for mental health services (80\%) and for charity/voluntary organizations $(78 \%)$; that the government should have a strategy to address mental health issues post-pandemic $(75 \%)$ and should make mental health a priority in their COVID-19 pandemic response (67\%); and that the pandemic will have long-term implications for the mental health of the nation (75\%). Only $23 \%$ of people 'somewhat' or 'strongly' agreed that the government had done enough to address the mental health impact of the pandemic.

The first step of hierarchical multiple regression explained $6 \%$ of the variance in mental health attitudes $(F(9,945)=6.73, p<0.001)$. Current or past mental health treatment, older age, and being born in Ireland were significantly associated with favourable mental health attitudes. The introduction of psychological variables in block 2 of the model explained an additional $11 \%$ of variance in attitudes $\left(R^{2}\right.$ change $\left.=0.11 ; F(10,935)=12.21, p<0.001\right)$, and the model as a whole explained $17 \%$ of variance in mental health attitudes $(F(19,935)=9.99, p<0.001)$. Older age and having a history of mental health treatment remained statistically associated with favourable mental health attitudes. The strongest correlate of favourable mental health attitudes was having higher levels of identification with others. Several other psychological factors were significantly correlated with favourable mental health attitudes including higher levels of internalizing distress, higher levels of internal locus of control, higher levels of conscientiousness, and lower levels of death anxiety (see Table 2 for full results). 
Table 2

Hierarchical multiple regression analysis of mental health attitudes during the COVID-19 pandemic

\begin{tabular}{lll}
\hline & Block 1 & Block 2 \\
\hline Sociodemographic variables & $\beta$ & $\beta$ \\
Age & $0.10^{* *}$ & $0.12^{* * *}$ \\
Females & $0.07^{*}$ & 0.03 \\
Non-Irish born & $-0.09 * *$ & -0.08 \\
City dwelling & -0.05 & -0.04 \\
Secondary education & 0.04 & 0.03 \\
Religious identification & -0.01 & -0.02 \\
Income level & -0.03 & -0.02 \\
Voter & -0.06 & -0.05 \\
Mental health treatment history & $0.15^{* * *}$ & $0.10^{* * *}$ \\
Psychological variables & & \\
Internalizing distress & & $0.15^{* * *}$ \\
Identification with others & & $0.25^{* * *}$ \\
Internal locus of control & & $0.09^{* *}$ \\
Openness & & 0.05 \\
Conscientiousness & & $0.10^{* *}$ \\
Extroversion & & -0.04 \\
Agreeableness & & 0.03 \\
Neuroticism & & 0.04 \\
Death anxiety & & $-0.11^{* *}$ \\
Resilience & & 0.00 \\
\hline R & &
\end{tabular}

$\beta$, standardized regression coefficient; $* p<.05, * * p<.01, * * * p<.001$

\section{Discussion}

The results show that a majority of Irish adults believed that mental health would be impacted by the COVID-19 pandemic, that the government had not done enough to address the impact of the pandemic on public mental health at the time of the survey, and that additional resources would be needed post-pandemic. These results are in line with the Mental Health Reform's 2018 report regarding the public's attitudes towards investing in mental health services. It was reported that $84 \%$ of people believed that too little focus was placed on mental health and was the highest of the six health problems measured (i.e. scoliosis, life-limiting conditions, cancer, alcohol misuse, and obesity). While only $23 \%$ of respondents from this study somewhat or strongly agreed that the government had done enough to address mental health issues due to the COVID-19 pandemic, $32 \%$ neither agreed nor disagreed, leaving $44 \%$ that somewhat or strongly disagreed. The high percentage of those who neither agreed nor disagreed may be due to respondents being unaware of the government response at the time of the survey as it was conducted in April of 2020, which was quite early in the pandemic. However, only $9 \%$ of respondents disagreed that the government should make mental health response to COVID-19 a priority.

Regarding the who and why of holding favourable or unfavourable attitudes towards mental health issues, older age was uniquely associated with having favourable attitudes towards mental 
health issues. Longitudinal data shows that empathy increase with age, ${ }^{17}$ and coupled with the finding that greater identification with others was the strongest correlate of holding favourable mental health attitudes, it is highly probable that a psychological disposition towards empathy and compassion for others is central to believing that more should be done to help those in need of mental health care. Moreover, having experienced mental health treatment (current or past) and reporting higher levels of internalizing distress in the present were both uniquely associated with holding favourable mental health attitudes. It is, therefore, highly probable that experiencing mental health problems, and using mental health care services, is associated with having favourable attitudes towards mental health services. Given that mental health problems are very common in the population with approximately $45 \%$ suffering from a mental health disorder at any point in time and $86 \%$ suffering from a mental health disorder by middle age, ${ }^{18}$ this may help to explain the overwhelmingly positive mental health attitudes of the public. In addition, those who are more conscientious, who believe they are in control of events in their lives, and have higher levels of death anxiety were also more likely to hold favourable mental health attitudes. Younger members of the community who have not experienced mental health services would be an ideal demographic to target in order to increase favourable attitudes.

\section{Implications for Behavioural Health}

There is evidence of increasingly positive attitudes towards people with mental health problems over time, ${ }^{19}$ and these findings indicate that in the context of COVID-19, the Irish public hold very favourable attitudes towards mental health issues and value greater government investment in addressing mental health needs. Additionally, when formulating and implementing strategies to increase favourable attitudes towards mental health issues, these sociodemographic and psychological features should be considered. However, evidence suggests that this group is a minority within the general population.

\section{Declarations}

Ethics Approval The authors assert that all procedures contributing to this work comply with the ethical standards of the relevant national and institutional committee on human experimentation with the Helsinki Declaration of 1975, as revised in 2008. Informed consent was obtained, and ethical approval was provided by the Ethics Committee of the University of Sheffield (reference number 033759).

Conflict of Interest The author POF works for a mental health charity that advocates and lobbies for improved mental health services in Ireland.

\section{References}

1. Torjesen, I. Covid-19: Mental health services must be boosted to deal with "tsunami" of cases after lockdown. British Medical Journal, 2020;369:m1994. https://doi.org/10.1136/bmj.m1994

2. Robinson E, Sutin AR, Daly M, et al. A systematic review and meta-analysis of longitudinal cohort studies comparing mental health before versus during the COVID-19 pandemic in 2020. Journal of Affective Disorders. 2022;296:567-576. https://doi.org/10.1101/2021. 03.04.21252921 
3. Shevlin M, Butter S, McBride O, et al. Refuting the myth of a 'tsunami' of mental ill-health in populations affected by COVID-19: evidence that response to the pandemic is heterogeneous, not homogeneous. [Published online ahead of print, 2021 Apr 20]. Psychological Medicine. https://doi.org/10.1017/S0033291721001665

4. Dewa, L. H. Response to Social distancing in covid-19: What are the mental health implications? British Medical Journal. 2020;369, m1379. Retrieved from https://doi.org/10.1136/bmj.m1379

5. McBride O, Murphy J, Shevlin M, et al. Monitoring the psychological, social, and economic impact of the COVID-19 pandemic in the population: Context, design and conduct of the longitudinal COVID-19 psychological research consortium (C19PRC) study. International Journal of Methods in Psychiatric Research. 2021;30(1):e1861. https://doi.org/10.1002/mpr.1861

6. Central Statistics Office of Ireland. Census 2016 Reports. 2020. Retrieved from: https://www.cso.ie/en/census/

7. Flora DB, Curran PJ. An empirical evaluation of alternative methods of estimation for confirmatory factor analysis with ordinal data. Psychological Methods. 2004;9(4):466-491. https://doi.org/10.1037/1082-989X.9.4.466

8. Kenny DA, Kaniskan B, McCoach DB. The performance of RMSEA in models with small degrees of freedom. Sociological Methods \& Research. 2014; 44(3):486-507.

9. Cloitre M, Shevlin M, Brewin CR, et al. The International Trauma Questionnaire: development of a self-report measure of ICD-11 PTSD and complex PTSD. Acta Psychiatrica Scandinavica. 2018;138(6):536-546. https://doi.org/10.1111/acps.12956

10. Kroenke K, Spitzer RL, Williams JB. The PHQ-9: validity of a brief depression severity measure. Journal of General Internal Medicine 2001;16(9):606-613. https://doi.org/10.1046/j.1525-1497.2001.016009606.x

11. Spitzer RL, Kroenke K, Williams JB, et al. A brief measure for assessing generalized anxiety disorder: the GAD-7. Archives of Internal Medicine. 2006;166(10):1092-1097. https://doi.org/10.1001/archinte.166.10.1092

12. McFarland S, Webb M, Brown D. All humanity is my ingroup: a measure and studies of identification with all humanity. Journal of Personality and Social Psychology. 2012;103(5):830-853. https://doi.org/10.1037/a0028724

13. Rammstedt B, John OP. Measuring personality in one minute or less: a 10-item short version of the big five inventory in English and German. Journal of Research in Personality 2007;41:203-12.

14. Sapp SG, Harrod WJ. Reliability and Validity of a Brief Version of Levenson's Locus of Control Scale. Psychological Reports. 1993;72(2):539-550. https://doi.org/10.2466/pr0.1993.72.2.539

15. Tomás-Sábado J, Gómez-Benito J, Limonero JT. The Death Anxiety Inventory: a revision. Psychological Reports. 2005;97(3):793-796. https://doi.org/10.2466/pr0.97.3.793-796

16. Smith BW, Dalen J, Wiggins K, et al. The brief resilience scale: assessing the ability to bounce back. International Journal of Behavioral Medicine. 2008;15(3):194-200. https://doi.org/10.1080/10705500802222972

17. Oh J, Chopik WJ, Konrath S, et al. Longitudinal Changes in Empathy Across the Life Span in Six Samples of Human Development. Social Psychological and Personality Science. 2020;11(2):244-253. https://doi.org/10.1177/1948550619849429

18. Caspi A, Houts RM, Ambler A, et al. Longitudinal Assessment of Mental Health Disorders and Comorbidities Across 4 Decades Among Participants in the Dunedin Birth Cohort Study. Journal of the American Medical Association Network Open. 2020;3(4):e203221. https:// doi.org/10.1001/jamanetworkopen.2020.3221

19. Robinson EJ, Henderson C. Public knowledge, attitudes, social distance and reporting contact with people with mental illness 20092017. Psychological Medicine. 2019;49(16):2717-2726. https://doi.org/10.1017/S0033291718003677

Publisher's Note Springer Nature remains neutral with regard to jurisdictional claims in published maps and institutional affiliations. 